\title{
Exercise Testing in Hypertensive Patients Taking Different Angiotensin-Converting Enzyme Inhibitors
}

\author{
Maria Angela M. Q. Carreira, Leandro R. Tavares, Rafaela F. Leite, Jamila C. Ribeiro, \\ Antônio C. Santos, Karla G. Pereira, Guilhermo C. Velarde, Antonio Claudio L. Nóbrega
}

Niterói, RJ - Brazil

\begin{abstract}
Objective - To compare blood pressure response to dynamic exercise in hypertensive patients taking trandolapril or captopril.
\end{abstract}

Methods - We carried out a prospective, randomized, blinded study with 40 patients with primary hypertension and no other associated disease. The patients were divided into 2 groups $(n=20)$, paired by age, sex, race, and bodymass index, and underwent 2 symptom-limited exercise tests on a treadmill before and after 30 days of treatment with captopril (75 to $150 \mathrm{mg} /$ day) or trandolapril (2 to $4 \mathrm{mg} /$ day).

Results - The groups were similar prior to treatment $(p<0.05)$, and both drugs reduced blood pressure at rest $(p<0.001)$. During treatment, trandolapril caused a greater increase in functional capacity $(+31 \%)$ than captopril $(+17 \% ; p=0.01)$ did, and provided better blood pressure control during exercise, observed as a reduction in the variation of systolic blood pressure/MET (trandolapril: $10.7 \pm 1.9 \mathrm{mmHg} / \mathrm{Uvs} 7.4 \pm 1.2 \mathrm{mmHg} / \mathrm{U}, \mathrm{p}=0.02$; captopril: $9.1 \pm 1.4 \mathrm{mmHg} / \mathrm{Uvs} 11.4 \pm 2.5 \mathrm{mmHg} / \mathrm{U}, p=0.35$ ), $a$ reduction in peak diastolic blood pressure (trandolapril: $116.8 \pm 3.1 \mathrm{mmHg}$ vs $108.1 \pm 2.5 \mathrm{mmHg}, p=0.003$; captopril: $118.2 \pm 3.1 \mathrm{mmHg}$ vs $115.8 \pm 3.3 \mathrm{mmHg}, p=0.35)$, and a reduction in the interruption of the tests due to excessive elevation in blood pressure (trandolapril: $50 \%$ vs $15 \%$, $p=0.009$; captopril: $50 \%$ vs $45 \%, p=0.32$ ).

Conclusion - Monotherapy with trandolapril is more effective than that with captopril to control blood pressure during exercise in hypertensive patients.

Keywords: exercise test, arterial hypertension, antihypertensive therapy

Universidade Federal Fluminense

Mailing address: Maria Angela M. Q. Carreira - Rua Soldado João de Deus Araújo, 54 - 22765-380 - Rio de Janeiro, RJ, Brazil - E-mail: carreira@cardiol.br English version by Stela Maris C. e Gandour
Regular physical activity has been established as an important adjuvant in the treatment of hypertension based on the 3 following fundamental aspects: 1) aerobic and strength training reduces blood pressure at rest ${ }^{1}$; 2) regular aerobic exercises may help in controlling the risk factors for hypertension ${ }^{2}$, such as hyperinsulinemia and overweight; 3 ) risk factors for coronary heart disease, such as sedentary lifestyle, high cholesterol levels and hyperglycemia, are fought by regular physical activity, which reduces the risk of coronary events in hypertensive patients ${ }^{1-3}$. Based on this, the pharmacological treatment of hypertensive patients should aim at controlling blood pressure not only at rest, but also during exercise, and should not interfere with their physical capacity ${ }^{4}$. Because blood pressure behavior cannot be predicted during exercise through measurements at rest or other variables ${ }^{5}$, exercise testing should be included in the clinical assessment of hypertensive patients ${ }^{6}$.

Angiotensin-converting enzyme inhibitors are effective drugs in controlling blood pressure at rest. During exercise, these inhibitors did not interfere with the electrocardiographic variables, chronotropic response, functional capacity, and cardiac arrhythmias ${ }^{7,8}$. In regard to blood pressure response during exercise, however, previous studies ${ }^{9,10}$ showed that captopril, a sulfhydryl angiotensin-converting enzyme inhibitor, does not reduce peak systolic or diastolic blood pressure in hypertensive patients. Other angiotensinconverting enzyme inhibitors with modified chemical structure have been developed. The alterations in the chemical structure provided different characteristics, such as greater lipophilia, a longer time of action, and a more stable 24-hour control of blood pressure ${ }^{11}$. However, it has not been determined whether different angiotensin-converting enzyme inhibitors have different effects on blood pressure response to exercise. This study aimed at comparing blood pressure response to dynamic exercise in hypertensive patients taking captopril or trandolapril, a long-term nonsulfhydryl angiotensin-converting enzyme inhibitor. 


\section{Methods}

Adults of both sexes diagnosed with primary arterial hypertension and with an indication for pharmacological treatment ${ }^{3}$ were initially selected. The exclusion criteria were as follows: presence of other systemic diseases; inability to undergo exercise testing; electrocardiographic alterations interfering with the analysis of the ST segment (left bundle-branch block, left ventricular hypertrophy, conduction abnormalities); frequent or complex arrhythmias at rest or during exercise; systolic blood pressure at rest $\geq 200 \mathrm{mmHg}$ or diastolic blood pressure at rest $\geq 120 \mathrm{mmHg}$, or both.

We carried out a prospective, randomized, blinded study. The patients underwent physical examination, electrocardiography at rest, echocardiography, fundoscopy, and laboratory blood tests. The patients included in the study underwent exercise testing after a wash-out period of at least 3 days, depending on the time of action of the previously used drug. After the first test, the patients were randomized into 2 groups of treatment for 30 days as follows: captopril (group C - initial dosage of $75 \mathrm{mg} /$ day divided into 3 doses/day) or trandolapril (group T - initial dosage of $2 \mathrm{mg} /$ day in a single dose). The patients were followed up weekly, and the doses were increased when necessary to $150 \mathrm{mg} /$ day (C) or $4 \mathrm{mg} /$ day (T) according to the following criteria: systolic blood pressure $\geq 180$ or diastolic blood pressure $\geq 110 \mathrm{mmHg}$, or both, in the first 2 weeks, and systolic blood pressure $\geq 150 \mathrm{mmHg}$ or diastolic blood pressure $\geq 100$ $\mathrm{mmHg}$, or both, in the third week. After 30 days of treatment and dose adjustment, the patients underwent a second exercise test while they were taking captopril or trandolapril. The longest intervals between the last dose of the angiotensin-converting enzyme inhibitors and the exercise test were 6 hours $(\mathrm{C})$ and 12 hours $(\mathrm{T})$. Therefore, each patient underwent 2 exercise tests ( 1 with no medication and the other with captopril or trandolapril) using the same protocol and in the same period of the day. The study protocol was approved by the Committee on Ethics and Research of the Universidade Federal Fluminense, and all patients signed the informed written consent before entering the study.

Exercise testing was performed on a treadmill according to the Bruce treadmill protocol or its modified version, the choice being determined by age and the usual activities. Blood pressure was measured on the left arm according to the auscultatory method with a mercury-column sphygmomanometer, with the patient standing and at rest, every minute during exercise and at the first, second, third, and fifth minutes of recovery. Systolic and diastolic blood pressures were measured based on the I and V Korotkoff sounds, respectively. The electrocardiogram was continuously monitored with a3-lead system (MC5, aVF, and V2). Exercise continued until exhaustion, which was identified as the tenth level of the Borg treadmill exertion scale (0-10). In regard to the criterion of excessive elevation of blood pressure, the exercise was interrupted when systolic blood pressure was $\geq 250 \mathrm{mmHg}$ or diastolic blood pressure was $\geq 130 \mathrm{mmHg}$. Functional capacity was determined based on the aerobic functional deficit, considering the relation between the maximum $\mathrm{VO}_{2}$ reached and the maximum $\mathrm{VO}_{2}$ predicted for age, the negative values determining the best functional capacity.

The results were expressed as mean \pm standard deviation. The statistical analysis was based on the 2-way analysis of variance (ANOVA) for repeated measurements, in which the major factors were drug (captopril and trandolapril) and time (pre- and postdrug at rest, in different levels of exertion and recovery), accompanied by post hoc analysis with the Bonferroni test. Because diastolic blood pressure was not normally distributed, it was analyzed with a nonparametric method using the Wilcoxon test for paired samples and the Mann-Whitney test for independent samples. In the analysis of proportions, the normal test was used. The significance level of $\mathrm{p}<0.05$ was adopted for data analysis.

\section{Results}

One hundred and eight patients consecutively referred to our laboratory were initially recruited, 40 of whom completed the study. Twenty patients were excluded after the initial evaluation, 21 patients were excluded after the first exercise test, 23 during the follow-up at the outpatient care unit, and 4 patients were excluded after the test with the angiotensin-converting enzyme inhibitor. The most common causes of exclusion were as follows: presence of another associated cardiovascular disease $(\mathrm{n}=10)$; complex arrhythmia $(\mathrm{n}=7)$; mild arterial hypertension that normalized with exercise $(n=5)$; blood pressure at rest $\geq 200 / 120 \mathrm{mmHg}$ $(n=4)$; electrocardiographic alterations at rest $(n=3)$; and adverse effects of the angiotensin-converting enzyme inhibitors prescribed $(n=3)$. Thirteen patients voluntarily dropped out of the study.

The 2 groups ( $\mathrm{C}$ and $\mathrm{T}$ ) were similar in respect to age, sex, race, body mass index, and time elapsed since the diagnosis, as well as in respect to all variables obtained in the first test, ie, prior to treatment (tab. I).

Three patients were excluded from the study due to drug intolerance. One patient in each group had cutaneous hypersensitivity to the angiotensin-converting enzyme inhibitor, which was reverted after the drugs were suspended and adequate therapy initiated. Three patients had a cough after receiving captopril, which required interruption of the treatment in 1 patient due to the intensity of the symptom.

In both groups ( $\mathrm{C}$ and $\mathrm{T}), 55 \%$ of the patients had normal blood pressure levels $(<140 / 90 \mathrm{mmHg}$ ) after treatment. No difference in blood pressure at rest was observed in either group (SBP - T: $135 \pm 4 \mathrm{mmHg}$; C: $136 \pm 4 \mathrm{mmHg}$; $\mathrm{p}=0.75 ; \mathrm{DBP}-\mathrm{T}: 89 \pm 2 \mathrm{mmHg} ; \mathrm{C}: 90 \pm 2 \mathrm{mmHg} ; \mathrm{p}=0.59$ ).

With the use of angiotensin-converting enzyme inhibitors, systolic blood pressure with the patient in the orthostatic position diminished in group $\mathrm{T}$ (pre: $159 \pm 4 \mathrm{mmHg}$, post: $145 \pm 2 \mathrm{mmHg} ; \mathrm{p}=0.003$ ), but not in group $\mathrm{C}$ (pre: $161 \pm 4$ $\mathrm{mmHg}$, post: $150 \pm 1 \mathrm{mmHg}$; $\mathrm{p}=0.10$; fig. 1 ). On the other hand, diastolic blood pressure in the orthostatic position diminished in both groups ( $\mathrm{T}-$ pre: $107 \pm 2 \mathrm{mmHg}$, post: $98 \pm 3$ 


\begin{tabular}{|lccc|}
\hline \multicolumn{4}{|c|}{ Table I - Characteristics of the patients and results of exercise testing } \\
prior to treatment & & \\
\hline Variables & Trandolapril & Captopril & $\mathrm{P}$ \\
\hline Patients (n) & 20 & 20 & 1.00 \\
Male sex (\%) & 45 & 50 & 0.76 \\
White race (\%) & 40 & 50 & 0.54 \\
Age (years) & $55 \pm 2$ & $56 \pm 2$ & 0.79 \\
Body mass index (kg/m²) & $27.4 \pm 0.7$ & $27 \pm 0.9$ & 0.75 \\
Normal fundoscopy (\%) & 56 & 40 & 0.10 \\
Time of diagnosis (years) & $7 \pm 2$ & $7 \pm 2$ & 1.00 \\
Heart rate (bpm) & & & \\
Pre-test & $82 \pm 3$ & $78 \pm 3$ & 0.34 \\
Peak & $138 \pm 6$ & $139 \pm 6$ & 0.91 \\
Systolic BP (mmHg) & & & \\
Pre-test & $159 \pm 4$ & $161 \pm 4$ & 0.75 \\
Peak & $210 \pm 4$ & $215 \pm 4$ & 0.34 \\
Recovery (5 min) & $159 \pm 4$ & $157 \pm 4$ & 0.80 \\
Diastolic BP (mmHg) & & & \\
$\quad$ Pre-test & $107 \pm 2$ & $105 \pm 1$ & 0.20 \\
Peak & $117 \pm 3$ & $118 \pm 3$ & 0.80 \\
Recovery (5 min) & $102 \pm 2$ & $102 \pm 2$ & 0.83 \\
Double product \\
(x 10 3 mmHg.bpm)
\end{tabular}

$\mathrm{mmHg} ; \mathrm{p}=0.005$; - pre: $105 \pm 1 \mathrm{mmHg}$, post: $98 \pm 3 \mathrm{mmHg}$; $\mathrm{p}=0.04)$. Both drugs increased functional capacity as follows: a $31 \%$ increase in group $\mathrm{T}$ (pre: $+21.3 \pm 9.6 \%$, post: $15.7 \pm 7.7 \% ; \mathrm{p}=0.0006$ ) and only a $17 \%$ increase in group $\mathrm{C}$ (pre: $+4.4 \pm 9.3 \%$, post: $-11.5 \pm 9.6 \%$; $\mathrm{p}=0.03$ ), and this difference was significant $(\mathrm{p}=0.001)$. Peak systolic blood pressure increased in group $\mathrm{C}$ (pre: $215 \pm 4 \mathrm{mmHg}$, post: $224 \pm 5 \mathrm{mmHg} ; \mathrm{p}=0.03$ ), but did not change in group $\mathrm{T}$ (pre: $210 \pm 4 \mathrm{mmHg}$, post: $206 \pm 6 \mathrm{mmHg}$; $\mathrm{p}=0.40$; fig. 1 ). However, systolic blood pressure/MET did not change in group $\mathrm{C}$ (pre: $9.1 \pm 1.4 \mathrm{mmHg} / \mathrm{U}$; post: $11.4 \pm 2.5 \mathrm{mmHg} / \mathrm{U} ; \mathrm{p}=0.41$ ), but diminished in group $\mathrm{T}$ (pre: $10.7 \pm 1.9 \mathrm{mmHg} / \mathrm{U}$, post: $7.4 \pm 1.2$ $\mathrm{mmHg} / \mathrm{U} ; \mathrm{p}=0.02$; fig. 2). Peak diastolic blood pressure was reduced in group T (pre: $117 \pm 3 \mathrm{mmHg}$, post: $108 \pm 3 \mathrm{mmHg}$; $\mathrm{p}=0.003$ ), but not in group $\mathrm{C}$ (pre: $118 \pm 3 \mathrm{mmHg}$, post: $116 \pm 3$ $\mathrm{mmHg} ; \mathrm{p}=0.27$; fig. 1 ). During the test with angiotensinconverting enzyme inhibitors, limiting blood pressure occurred less frequently in group $\mathrm{T}$ (pre: $50 \%$ vs post: $15 \%$, $\mathrm{p}=0.009$ ) than in group $\mathrm{C}$ (pre: $50 \%$ vs post: $45 \%, \mathrm{p}=0.32$ ).

\section{Discussion}

The results showed that trandolapril, a long-lasting angiotensin-converting enzyme inhibitor, produced better blood pressure control during exercise than captopril, a short-lasting angiotensin-converting enzyme inhibitor, did.

Captopril and trandolapril normalized blood pressure at rest in 55\% of the patients. Although similar effects of captopril and trandolapril were previously shown by Richer et al ${ }^{12}$ in spontaneously hypertensive rats, these results do not agree with those obtained in a clinical study with 180 patients with light to moderate hypertension ${ }^{11}$, in which captopril was less effective in controlling blood pressure at rest (44\% with normal blood pressure after treatment) than trandolapril was (61\% with normal blood pressure after treatment). However, in that study, captopril was administered at the dosage of $50 \mathrm{mg}$ only twice a day, while our patients received $50 \mathrm{mg} 3$ times a day. These different dosages may explain the contrasting results.

Although the drugs were similar in controlling blood pressure during the outpatient care unit follow-up, trandolapril, but not captopril, reduced blood pressure in the orthostatic position, immediately before exercise testing. This difference may be due to a greater capacity of trandolapril to control blood pressure during situations of mental stress, such as the moments preceding an exercise test. In accordance with this hypothesis, Paran et al ${ }^{13}$ showed that atenolol inhibited blood pressure response to mental stress, in contrast with enalapril, which was not effective in controlling blood pressure alterations due to mental stress. Similarly, Grossman et a ${ }^{14}$ did not report changes in blood pressure response to mental stress in hypertensive patients treated with fosinopril, an angiotensin-converting enzyme inhibitor.

Trandolapril provided better control of systolic and diastolic blood pressure during exercise and allowed a greater number of patients to continue exercising and reach a greater intensity of exertion. On the other hand, captopril did not control the excessive increase in blood pressure during exercise, leading to a similar number of interruptions due to an increase in blood pressure prior to and after treatment. Similar results were obtained by Knugawa et al ${ }^{15}$ in hypertensive patients treated with alacepril, an angiotensin-converting enzyme inhibitor of the same pharmacological group as captopril. Although alacepril reduced mean blood pressure at rest and during exercise, the number of patients with limiting blood pressure during exercise was similar prior to and after treatment with alacepril.

In our study, both groups $\mathrm{C}$ and $\mathrm{T}$ showed an increase in tolerance for exertion, identified as a greater work load; trandolapril, however, had a more pronounced effect. In regard to trandolapril, this effect was partially due to a smaller number of patients whose exertion was interrupted due to an excessive elevation in blood pressure after treatment. The work load, however, increased in patients who reached exertion using trandolapril, suggesting a specific effect of the drug on tolerance for exertion. The mechanism involved may be related to a decrease in total peripheral vascular resistance and to a better perfusion of the skeletal musculature, as previously shown in rats ${ }^{12}$.

In our study, peak systolic blood pressure increased after treatment with captopril, but did not change in the group treated with trandolapril. This may have been due to an increase in work load, because the variation in systolic blood pressure/MET did not change after treatment with captopril and diminished after treatment with trandolapril. These results differ from those of previous studies, which showed that the use of captopril did not change or reduce 


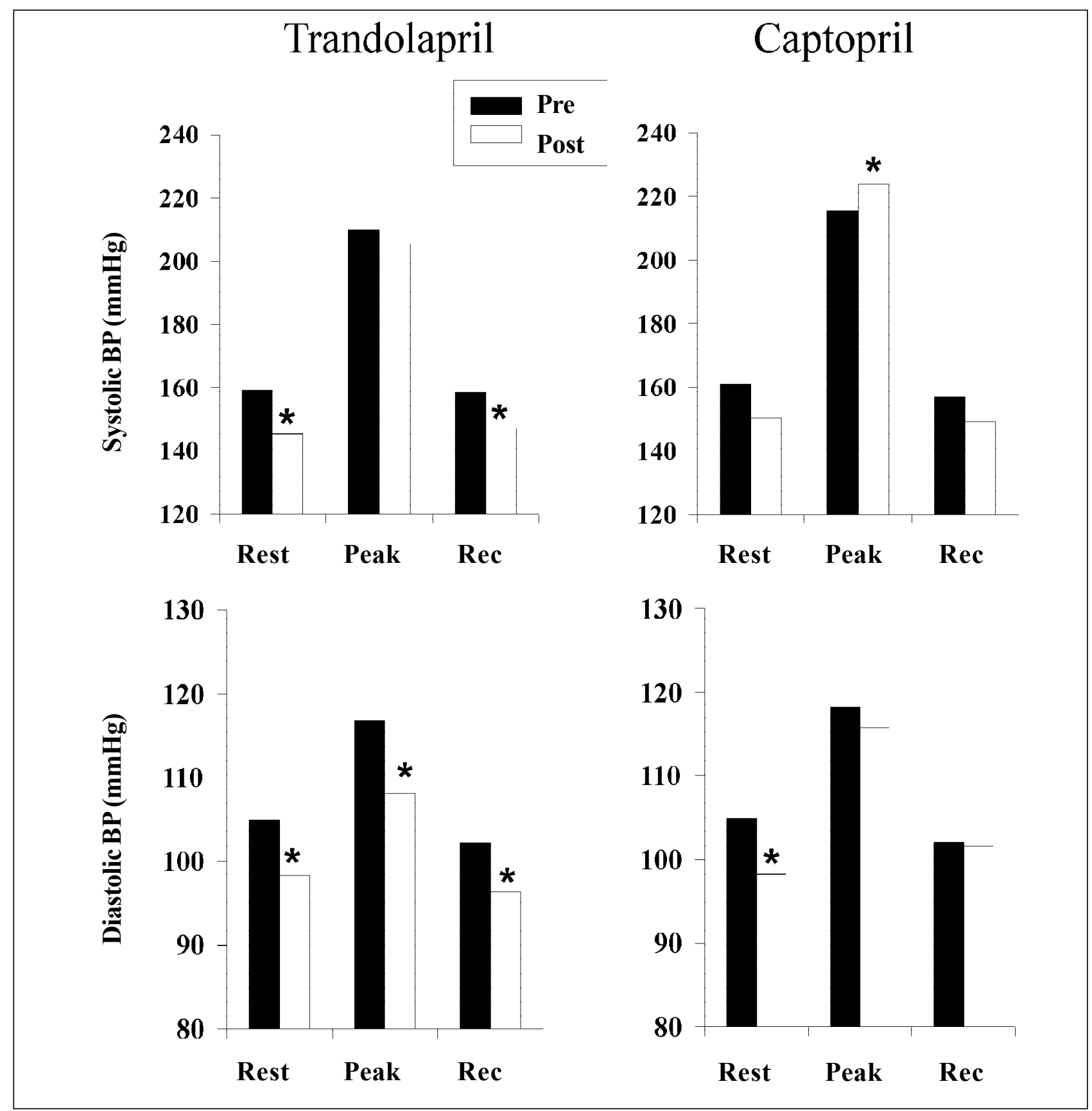

Fig. 1 - Systolic (upper) and diastolic (lower) blood pressure prior to (pre) and after (post) treatment with trandolapril ( $\mathrm{n}=20$, left) or captopril ( $\mathrm{n}=20$; right) at rest (Rest), peak exertion, and 5 minutes after exertion $(\operatorname{Rec})$. Values are mean $\pm \mathrm{SD} ; * \mathrm{p}<0.05$ vs prior to the same drug.

blood pressure at peak exertion ${ }^{10,16}$. Handa et al ${ }^{16}$ assessed normotensive individuals with ergometers, making the comparison with our results difficult. The study by Kostis et al ${ }^{10}$ reported a reduction in systolic blood pressure at peak exertion using a similar methodology, ie, hypertensive patients exercising on a treadmill according to the Bruce protocol. The authors, however, reported that the patients did not reach maximum exertion, unlike our study, in which all patients reached maximum exertion, which was identified with the subjective exertion scale (Borg treadmill exertion scale), except when the exercise was interrupted by an exaggerated blood pressure response.
The studies about trandolapril and exercise are very few. Predel et al ${ }^{17}$ assessed healthy well-trained individuals, and concluded that $2 \mathrm{mg}$ of trandolapril do not alter tolerance for exertion or blood pressure response to exercise. Our data differ from these results, especially in regard to diastolic blood pressure, which significantly decreases after treatment with trandolapril. A direct comparison between these 2 studies is difficult due to the different characteristics of the individuals (healthy trained vs hypertensive nontrained).

The mechanisms involved in better blood pressure control during exercise produced by trandolapril as compa- 


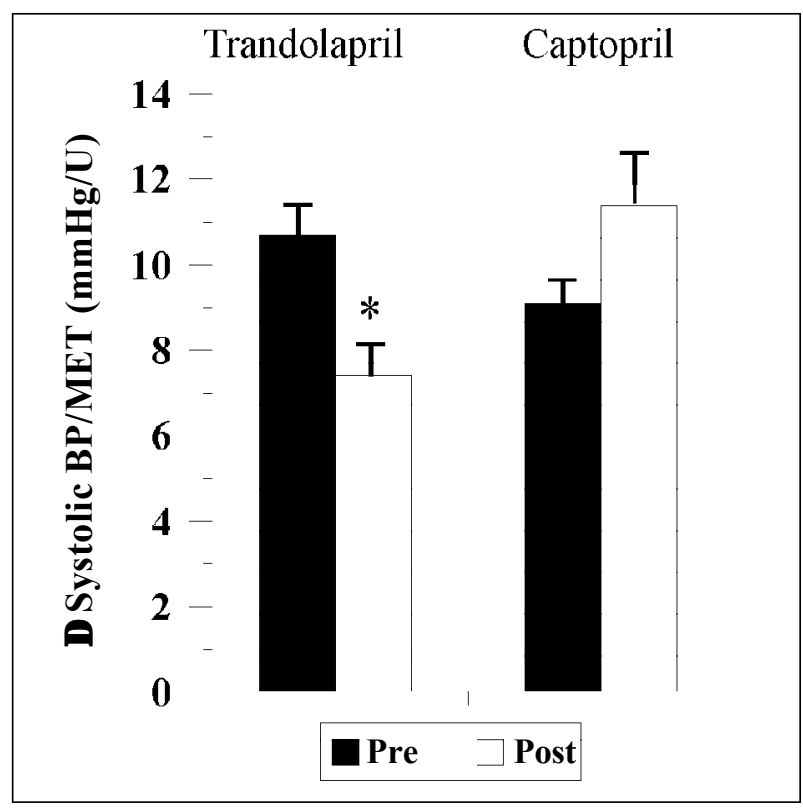

Fig. 2 - Variation in systolic blood pressure $(\triangle \mathrm{SBP})$ corrected by work load at peak exertion (MET) prior to (pre) and after (post) treatment with trandolapril ( $\mathrm{n}=20)$ or captopril $(\mathrm{n}=20)$. Values are mean $\pm \mathrm{SD} ; * \mathrm{p}=0.02$ vs pre trandolapril.

red with that produced by captopril have not been well understood. A basic difference between these 2 drugs is lipophilia, which is greater with trandolapril. The greater degree of the drug's lipophilia causes a smaller variability in blood pressure in 24 hours ${ }^{18}$. In addition, greater lipophilia results in a better capacity to penetrate the cell membranes, including that of the target tissue of the angiotensin-converting enzyme, causing a more effective inhibition of the renin-angiotensin system ${ }^{19}$.

Aldigier et al ${ }^{20}$ reported that the inhibitory effect of captopril on the plasma levels of angiotensin at rest disappears with exercise, probably due to the production of angiotensin II by other enzymes that are not blocked by the drug. Studies on trandolapril are required to determine its capacity to block angiotensin II during exercise.

Because trandolapril and captopril have different times of action and food intake interferes with the absorption of captopril, changes in the plasma levels of the drugs may have occurred during exercise and may partially explain the different effects on blood pressure response. However, we observed that the maximal interval between the last dose and test performance was 6 hours for captopril and 12 hours for trandolapril. In addition, patients were instructed to take captopril 1 hour before meals, minimizing, therefore, the interferences resulting from variations in the plasma concentration of the drug during the test. Many other angiotensin-converting enzyme inhibitors are available with intermediate degrees of lipophilia and times of action, and we cannot extend our results to these other compounds.

Physical exercise is part of daily life activity and should be formally prescribed to hypertensive patients. Lack of blood pressure control during exercise in these patients may lead to lesions in target organs, as shown by ambulatory blood pressure monitoring ${ }^{21}$. Although trandolapril was more effective than captopril in controlling blood pressure during exercise, larger longitudinal studies are required to confirm these findings.

\section{References}

1. U.S. Department of Health and Human Services, Public Health Services, National Heart Lung and Blood Institute. The sixth report of the joint national committee on prevention, detection and treatment of high blood pressure. Arch Intern Med 1997; 157: 2413-45.

2. American Association of Cardiovascular and Pulmonary Rehabilitation: Guidelines for Cardiac Rehabilitation Programs. $3^{\text {rd }}$ ed. Champaign: Human Kinetics, 1999.

3. World Health Organization - International Society of Hypertension. Guidelines for the Management of Hypertension. J Hypertens 1999; 17: 151-78.

4. Rudd P, Hagar RW. Hypertension mechanisms, diagnosis, and therapy. In: Topol EJ (editor). Textbook of Cardiovascular Medicine. New York: Lippincott Raven; 1998: 109-43.

5. Miyai N, Arita M, Morioka I, Miyashita K, Nishio I, Takeda S. Exercise BP response in subjects with high-normal BP. J Am Coll Cardiol 2000; 36: 1626-31.

6. ACC/AHA Committee on exercise testing. Guidelines for exercise testing. J Am Coll Cardiol 1997; 30: 260-315.

7. Palatini P, Bongiovi S, Mario L, Mormino P, Raule G, Pessina AC. Effects of ACE inhibition on endurance exercise haemodynamic in trained subjects with mild hypertension. Eur J Clin Pharmacol 1995; 48: 435-9.

8. González-Juanatey JR, Reino AP, Garcia-Acuña JM, et al. Maintenance of blood pressure control and left ventricular performance with small doses of enalapril. Am J Cardiol 1999; 83: 710-23.

9. Manhem P, Bramnert M, Hulthén UL, Hökfelt B. The effect of captopril on catecholamines, renin activity, angiotensin II and aldosterone in plasma during physical exercise in hypertensive patients. Eur J Clin Invest 1981; 11: 389-95.

10. Kostis JB, Shindles DM, Moreyra AE, Ruddy MC, Schneider S, Cosgrove N. Differential exercise effects of captopril and nadolol in patients with essential hypertension. Angiology 1992; 43: 647-52.

11. Pauly NC, Safar ME. Comparison of the efficacy and safety of trandolapril and cap- topril for 16 weeks in mild-to-moderate essential hypertension. Investigator study group. J Cardiovasc Pharmacol 1994; 23(suppl 4): S73-S6.

12. Richer C, Doussau M, Giudicelli JF. Systemic and regional haemodynamic profile of five angiotensin I converting enzyme inhibitors in the spontaneously hypertensive rat. Am J Cardiol 1987; 59: 12D-17D.

13. Paran E, Neumann L, Cristal N, Lowenthal DT. Response to mental and physical stress before and during adrenoreceptor blocker and angiotensin-converting enzyme inhibitor treatment in essential hypertension. Am J Cardiol 1991; 68: 1362-6.

14. Grossman E, Messerli FH, Oren S, Soria F, Schmeider R. Disparate cardiovascular response to stress tests during isradipina and fosinopril therapy. Am J Cardiol 1993; 72: 574-9.

15. Kinugawa T, Kitamura H, Ogino K, et al. Effect of alacepril on blood pressure and neurohumoral factors at rest and during exercise in patients with essential hypertension. Br J Clin Pharmacol 1992; 34: 366-9.

16. Handa K, Sasaki J, Tanaka H, et al. Effects of captopril on opioid peptides during exercise and quality of life in normal subjects. Am Heart J 1991; 122: 1389-94.

17. Predel HG, Rohden C, Heine O, Prinz U, Rost E. ACE inhibition and physical exercise: studies on physical work capacity, energy metabolism, and maximum oxygen uptake in well-trained, healthy subjects. J Cardiovasc Pharmacol 1994; 23 (suppl 1): S25-S8.

18. Genes N, Lemoine G, Duguet A, et al. Comparative lipophilia of trandolapril and other converting enzyme inhibitors. Therapie 1995; 50: 131-6.

19. Meredith PA, Perloff D, Mancia G, Elliott HL. Blood pressure variability and its implications for anti-hypertensive therapy. Blood Pressure 1995, 4: 5-11.

20. Aldigier JC, Huang H, Dalmay F, et al. Angiotensin-converting enzyme inhibition does not suppress plasma angiotensin II increased during exercise in humans. J Cardiovasc Pharmacol 1993; 21: 289-95.

21. Devereaux RB, Pickering TG. Relationship between the level, pattern and variability of ambulatory blood pressure and target-organ damage in hypertension. J Hypertens 1991; 9(suppl II): II53-II60. 